\title{
French trainers' beliefs on problems and computing
}

\section{Croyances des formateurs français sur les problèmes et le calcul}

\author{
Richard Cabassut ${ }^{1 *}$ and Arnaud Simard $^{2}$ \\ ${ }^{1}$ LISEC-EA2310, INSPE Université de Strasbourg, France. \\ ${ }^{2}$ Franche-Comté University, France.
}

\begin{abstract}
We present an exploratory research based on an online questionnaire to better understand the French trainers' beliefs on problems and computing from grades 1 to 3 of primary school. We explain the French context of the new 2016 curriculum and of the 2018 report on mathematics teaching that motivates the content and the interest of the questionnaire. The results show trainers' heterogeneity although some beliefs are dominant. A cluster analysis proposes three trainer's types that could help to organize the training on teaching of problems and computing. This research could go on with paragons' semi-directed interviews.
\end{abstract}

\begin{abstract}
Résumé. Nous présentons une recherche exploratoire basée sur un questionnaire en ligne pour mieux comprendre les croyances des formateurs français sur les problèmes et le calcul de la lère à la 3ème année du primaire. Nous expliquons le contexte français du nouveau cursus 2016 et du rapport 2018 sur l'enseignement des mathématiques qui motive le contenu et l'intérêt du questionnaire. Les résultats montrent l'hétérogénéité des formateurs bien que certaines croyances soient dominantes. Une analyse par grappes propose trois types de formateurs qui pourraient aider à organiser la formation sur l'enseignement des problèmes et le calcul. Cette recherche pourrait se poursuivre avec des entretiens semi-dirigés de parangons.
\end{abstract}

\section{Aim of the research}

France has a strong tradition of problem solving in primary school [1]. In the new 2016 curriculum, two topics are focused on: problem solving and computing [2]. Problem solving brings meaning to computing and computing enables to solve problems. The recent report on mathematics teaching supervised by Fields medal Villani [3] led to the development of inservice teacher training. We took part in two regional trainings for primary school trainers

\footnotetext{
* Corresponding author: richard.cabassut@unistra.fr
} 
about problem solving and computing. Before the beginning of the training session the trainers could fill out an anonymous online questionnaire about their beliefs on problem solving, computing and teachers' training. We adopt the definitions given by [4], particularly: "Beliefs - psychologically held understandings, premises, or propositions about the world that are thought to be true. Beliefs are more cognitive, are felt less intensely, and are harder to change than attitudes [...] Knowledge - beliefs held with certainty or justified true belief". In this conception of beliefs, we consider knowledge as a kind of beliefs. The importance of beliefs was already studied by different research teams $[5,4,6]$. We investigate the beliefs about problem solving and computing. We start by studying trainers' beliefs in order to help teachers' training. About trainers' beliefs on training, we use Bandura's theory on selfconfidence and self-efficacy [7] and previous research on teachers' practices $[8,9]$.

\section{Method of conception of the online questionnaire}

The questionnaire is composed of 64 questions divided into four parts, with either multiple choice questions or Lickert scale questions. The choice of the question in this exploration phase is based on previous research showing the importance of the question, or based on both authors' beliefs when no research arguments were found. Let us illustrate the different parts of the questionnaire. In the biographical part, 9 questions inform about trainers' biography variables: gender, age, trainer's type, teaching conditions in the trainer's area of intervention, training conditions in the trainer's area of intervention, experience in training, training received by the trainer (initially, in mathematics, to become a trainer). In a previous research, [9] has shown how relevant these variables were. For example, for the trainer's type the question is: What is your current professional activity: - inspector of the school district? pedagogical advisor? part-time trainer? - other? Let us describe these different trainers 'type. An inspector of the school district is in charge of teacher's evaluation, professional development and teaching organization in a school district gathering several primary schools. A pedagogical advisor is a former teacher who is no more in charge of a class and who assists the school district inspector. A part-time trainer is a half-time primary school teachers and half-time primary school trainer. He passes an examination to become part-time trainer. Others could be primary school teacher, full time trainer at university, administrative staff in education. For the teaching conditions in the trainer's area of intervention, the question is: Specify if in your geographical area of intervention, the teaching conditions appear: difficult, - varied, - easy. The following parts of the questionnaire concern problem solving (12 questions), computing (18 questions) and training (25 questions). The questions are based on the following Lickert scale formulation: You are asked here for your opinion about a statement and not what the syllabus prescribes. For any of the following statements indicate your degree of agreement: - agree, - rather agree, - neutral, - rather disagree, - disagree. The content of the statement was inspired by the official resources produced by the Ministry of Education (MEN 2018, 2019). The different statements are presented in the following frequency table.

\section{Method of analysis of results}

The sample of answers to the questionnaire was not constructed on a representative basis but on an exploratory one according to Tukey's exploratory approach [10]. The two authors took part in a one-day training for primary school trainers in two different regional areas, one in Paris area in October 2018, and the other one in East of France in December 2018. Two weeks before the training, each participant received the online questionnaire and could voluntarily and anonymously answer: we got 124 answers. The statistical analysis uses SPAD 
software which provides frequency tables, cross-tabulation and cluster analysis. Every question can be considered as a variable and the different answers to this question as the different modalities of the variable. We begin with a frequency analysis that enables to choose the active variables for the following cluster analysis. For the cluster analysis, we observe the percentage of answers of every modality of the variable. If a variable has no modality with more than $66 \%$ of answers we will consider this variable as active variable and use it to build the clusters with SPAD software. We tried the cluster analysis with other choices for active variables (for example with variables from the parts problem solving and computing) but it was difficult for us to interpret the clusters proposed by the software. In this case this active variable divides the population in two comparable blocks. The other variables (where a modality is dominant with more than $66 \%$ of answers) will be reintroduced later as illustrative variables to illustrate the clusters. For the cluster analysis we begin with a multiple correspondence analysis (MCA) on the actives variables. Then we apply a hierarchical ascendant classification (HAC or cluster analysis) by using the distances measured on the first coordinates between trainers on the trainers' first coordinates on the factorial axes determined by the MCA. We limited to a 3-clusters analysis because it was difficult to interpret the clusters if we choose a clustering with more than 3 clusters. To interpret a cluster produced by the software, an active variable is a splitting variable for this cluster if a modality of this variable has a percentage of answers in this cluster that is very different than the percentage in the whole population. Every cluster will be described with these modalities of splitting variables. The other non-active variables are called illustrative variables. For a cluster, an illustrative variable is a split variable if a modality of this variable has a percentage of answers in this cluster that is very different than the percentage in the whole population. The split variables of a cluster help to describe this cluster. We will now present the results of this frequency and cluster analysis.

\section{Results of frequency analysis}

From 124 people, results about biographical part are as following: 54\% of answers are issued from the first regional area, $62 \%$ are women, $47 \%$ are young (it means less than the median age with 48 years as median age), from the trainer' type part $55 \%$ are pedagogical trainers, $30 \%$ are part-time trainer, $9 \%$ are inspectors and $6 \%$ are others, $90 \%$ have varied teaching condition in their area and 5\% difficult ones, $74 \%$ have varied teaching condition in their area and $13 \%$ difficult ones, $48 \%$ are less experienced (it means less than the median duration with 7 years as median number of years of experience), $62 \%$ have a nonscientific initial education, $72 \%$ are satisfied in their current job with their level of mathematics education, $73 \%$ are satisfied in their current job with their level of training as a teacher trainer (apart from mathematics). These results show a heterogeneity of biographical features even if some of them are dominant. We will discover in the cluster analysis which variables explain the clusters. For the part on problem solving, computing, and training beliefs the following table gives the percentages.

Table 1. Problems.

\begin{tabular}{|c|c|c|c|}
\hline Problems & agree & neutral & disagree \\
\hline $\begin{array}{c}\text { In the three first years of elementary school it is necessary to rely on } \\
\text { a diagram or a table to solve a problem }\end{array}$ & 54 & 14 & 32 \\
\hline $\begin{array}{c}\text { Problems with several steps can be proposed from the beginning of } \\
\text { the three first years of elementary school }\end{array}$ & 81 & 10 & 9 \\
\hline
\end{tabular}




\begin{tabular}{|c|c|c|c|}
\hline $\begin{array}{c}\text { Problems modeled by subtraction are more difficult than problems } \\
\text { modeled by addition }\end{array}$ & 32 & 21 & 47 \\
\hline $\begin{array}{c}\text { Within the category of additive problems there are several types of } \\
\text { problems of different difficulty levels }\end{array}$ & 94 & 3 & 3 \\
\hline $\begin{array}{c}\text { The subtraction must be assimilated to a withdrawal situation } \\
\text { Typical problem solving examples should be used as a systematic } \\
\text { reference when solving problems }\end{array}$ & 56 & 26 & 19 \\
\hline $\begin{array}{c}\text { By using a similar schematic representation in different problems } \\
\text { their understanding is facilitated }\end{array}$ & 71 & 18 & 11 \\
\hline $\begin{array}{c}\text { It is important to propose problems with several steps from the three } \\
\text { first years of elementary school }\end{array}$ & 77 & 18 & 6 \\
\hline $\begin{array}{c}\text { In problem solving one must first organize an individual resolution } \\
\text { time before a group time }\end{array}$ & 75 & 12 & 13 \\
\hline $\begin{array}{c}\text { If pupils improve their numeracy performance, they will find it } \\
\text { easier to find the connection between the problem posed and the } \\
\text { operations to which it belongs. }\end{array}$ & 52 & 13 & 36 \\
\hline $\begin{array}{c}\text { If no student finds the method expected to solve a problem, the } \\
\text { teacher can then propose the expected method. }\end{array}$ & 57 & 19 & 24 \\
\hline $\begin{array}{c}\text { To learn how to solve a problem, students must learn to make } \\
\text { assumptions. }\end{array}$ & 81 & 12 & 7 \\
\hline
\end{tabular}

Table 2. Computing.

\begin{tabular}{|c|c|c|c|}
\hline Computing & agree & neutral & disagree \\
\hline $\begin{array}{c}\text { The meaning of the four operations should be acquired from grade } \\
1\end{array}$ & 72 & 14 & 14 \\
\hline $\begin{array}{c}\text { The four operations should be done with columns writing in grade } \\
\text { 1, but with small numbers }\end{array}$ & 17 & 15 & 68 \\
\hline $\begin{array}{c}\text { The symbolization with + and = should be introduced from grade 1 } \\
\text { 10 }\end{array}$ & 87 & 8 & 5 \\
\hline $\begin{array}{c}\text { At the beginning of grade 1 pupils should have acquired the ability } \\
\text { to enumerate and memorize the oral sequence of numbers up to 30 }\end{array}$ & 76 & 16 & 8 \\
\hline $\begin{array}{c}\text { At the end of grade 1 a pupil should know the supplements to make } \\
\text { At the end of grade 1 a pupil should know the additive } \\
\text { decompositions of numbers less than or equal to 10 }\end{array}$ & 98 & 2 & 1 \\
\hline $\begin{array}{c}\text { At the end of grade 1 a pupil should know the double of the } \\
\text { numbers less than 10 }\end{array}$ & 95 & 4 & 1 \\
\hline In grade 2 the multiplication tables should be memorized & 40 & 28 & 32 \\
\hline $\begin{array}{c}\text { The understanding of the decimal number system for numbers less } \\
\text { than 100 should be expected at the end of grade 1 }\end{array}$ & 56 & 27 & 17 \\
\hline $\begin{array}{c}\text { At the end of grade 3 the properties of commutativity and } \\
\text { distributivity can be used in computing }\end{array}$ & 81 & 16 & 3 \\
\hline
\end{tabular}




\begin{tabular}{|c|c|c|c|}
\hline $\begin{array}{l}\text { From grade } 1 \text { pupils should discuss division in sharing or grouping } \\
\text { situations. }\end{array}$ & 90 & 9 & 2 \\
\hline $\begin{array}{l}\text { The multiplication technique written in columns must be studied } \\
\text { from grade } 3\end{array}$ & 65 & 22 & 13 \\
\hline $\begin{array}{l}\text { The division technique written in columns must be studied from } \\
\text { grade } 4\end{array}$ & 66 & 22 & 12 \\
\hline $\begin{array}{l}\text { The mental computing must be practiced on average } 15 \text { minutes a } \\
\text { day }\end{array}$ & 91 & 6 & 3 \\
\hline $\begin{array}{l}\text { A mental computing session should be scheduled daily (short } \\
\text { workout session alternating with lengthy brainstorming sessions on } \\
\text { procedures). }\end{array}$ & 99 & 1 & 0 \\
\hline At the end of grade 3 all the multiplication tables can be requested & 70 & 22 & 8 \\
\hline $\begin{array}{l}\text { The techniques of mental, in written lines or in written columns } \\
\text { computing must be taught explicitly }\end{array}$ & 94 & 5 & 1 \\
\hline $\begin{array}{l}\text { Written columns computing has priority over other forms of } \\
\text { computing (mental, written lines, instrumented) }\end{array}$ & 5 & 7 & 88 \\
\hline
\end{tabular}

Table 23 Training.

\begin{tabular}{|c|c|c|c|}
\hline Training & & & \\
\hline During training, working in small groups is important & 93 & 7 & 0 \\
\hline During training, the application of official syllabus is important & 89 & 10 & 2 \\
\hline During training, the use of official resources is important & 93 & 7 & 0 \\
\hline Evaluating a problem-solving training is easy & 7 & 37 & 56 \\
\hline To prepare a training takes too much time & 62 & 30 & 8 \\
\hline I feel able to develop evaluation criteria for a training & 38 & 35 & 27 \\
\hline I feel able to use the mistakes of the trained teachers to facilitate & 65 & 23 & 11 \\
\hline I feel able to design problem-solving training tasks & 56 & 26 & 19 \\
\hline I feel able to design training tasks on computing & 58 & 26 & 1 \\
\hline Trained people are hard to motivate during training & 30 & 41 & 29 \\
\hline The heterogeneity of teachers taking part to the training is a & 53 & 11 & 36 \\
\hline difficulty for the training & & & \\
\hline I do not have enough training resources on computing & 40 & 31 & 29 \\
\hline The evaluation of a training on computing is easy & 17 & 42 & 41 \\
\hline Distance training is difficult to evaluate & 68 & 20 & 12 \\
\hline In training, trust is difficult because of hierarchical links & 28 & 32 & 40 \\
\hline I do not have enough training resources on problem solving & 43 & 33 & 24 \\
\hline I do not have enough training resources on computing & 40 & 31 & 29 \\
\hline
\end{tabular}




\begin{tabular}{|c|c|c|c|} 
Teachers are giving insufficient attention to mental computing & 56 & 26 & 19 \\
\hline Teachers are giving insufficient attention to instrumented computing & 45 & 30 & 25 \\
\hline Among teachers the notion of problem is not clear & 67 & 23 & 10 \\
\hline $\begin{array}{c}\text { To give the good methods to solve a problem is a good way to train } \\
\text { for problem solving }\end{array}$ & 16 & 27 & 57 \\
\hline $\begin{array}{c}\text { To give the good methods to compute is a good way to train for } \\
\text { computing }\end{array}$ & 28 & 27 & 45 \\
\hline There is not enough time for in-service training & 28 & 17 & 5 \\
\hline Teachers taking part to a training are not used to collaborate & 46 & 22 & 32 \\
\hline
\end{tabular}

We observe an heterogeneity of the beliefs. Some beliefs are opposite to official prescription. For example, $14 \%$ disagree with the statement: The meaning of the four operations should be acquired from grade 1 . This statement is issued from ministry prescription on grade 1 [11]. Some beliefs are controversial. For example, $71 \%$ agree the statement: By using a similar schematic representation in different problems their understanding is facilitated. It is particularly true in France where Singapore method with its bar representation is sometimes strongly promoted $[3,2]$. But for [12] about the different registers of representation "Mathematical comprehension begins when coordination of registers starts up. Mathematical thinking processes depend on a cognitive synergy of registers of representation". The variety of schematic representation helps to understand and the use of similar schematic representation could hide a misunderstanding. Some beliefs express a need of resources (including training for trainers). For example, only $58 \%$ agree to feel able to design problemsolving training tasks.

\section{Results of cluster analysis}

The cluster analysis enables to relate different variables. A first cluster gathers 77 individuals $(62 \%)$. In this cluster we find the trainers who are positive and self-confident about problem solving, computing and training. Much more than in the whole population they agree that they feel able to design training tasks on computing and on problem solving, and they disagree that they do not have enough training resources on computing and problem solving, that the teachers are giving insufficient attention to mental computing or instrumented computing, that to give the good methods to solve a problem is a good way to train for computing, that trust is difficult in training, because of hierarchical links. About the biographical variables, much more than in the whole population we find in this cluster pedagogical advisors, trainers from the second regional area (East of France), satisfied by their level of mathematics education, less experienced, with scientific initial education and working in an area with varied teaching conditions.

A second cluster gathers 24 individuals (20\%). We find trainers who are rather negative and less self-confident about problem solving, computing and training. Much more than in the whole population they agree that they do not have enough training resources on computing and problem solving, that trust is difficult because of hierarchical links, that to prepare a training takes too much time, that trained people are hard to motivate during training, and they disagree that they feel able to design training tasks on computing and on problem solving, to use the mistakes of the trained to facilitate their training, to develop evaluation criteria for a training, that the evaluation of a training on computing is easy. About the biographical variables, much more than in the whole population we find in this cluster 
trainers from the first regional place (Paris area), part-time trainer, with non-scientific initial education and working in an area with easy teaching conditions.

A third cluster gathers 33 individuals (27\%). Much more than in the whole population, we find trainers who are neutral about problem solving, computing and training, with trainer type other than inspector, pedagogical advisor or part-time trainer, more experienced, and not satisfied by their level of mathematics education.

\section{Conclusion and implications for trainers' and teachers' training and ongoing research}

This exploration study has shown the heterogeneity of trainer's beliefs. This heterogeneity questions trainers' training and efficiency of official resources and curriculum. The cluster analysis has distinguished three main trainer's types in their relation to problem solving, computing and training: the positive one, the negative one and the neutral one, with a role played by trainer's types, experience, regional area, mathematics level of education, teaching conditions of the trainers' working area. Trainers' and teachers' training are the ideal places to think about the different arguments about these varied beliefs, to confront these arguments with the syllabus prescriptions, to produce resources and training scenarios, to have a feedback about difficulties. This research will go on into two directions. First we plan to have semi-directed interviews with paragons of the different clusters. These interviews have to clarify the different arguments about paragon's beliefs, to explain the difference between the two regional areas, to describe the need of resources and training on problem solving and computing, to explain why pedagogical advisors look more positive than part-time trainers. Then we plan to have a second questionnaire with the same trainers after a while to study the change in these beliefs.

\section{References}

1. Artigue, M., Houdement, C., Problem solving in France: didactic and curricular perspectives, ZDM Mathematics Education 39:365-382 (2007).

2. MEN (Ministère de l'Education Nationale), Enseignement du calcul: un enjeu majeur pour la maîtrise des principaux éléments de mathématiques à l'école primaire. La résolution de problèmes à l'école élémentaire, Bulletin Officiel Spécial de l'Education Nationale $n^{\circ} 3$ du 26 avril 2018. 10-19 (2018).

3. Villani C., Torossian C., 21 mesures pour l'enseignement des mathématiques, Ministère de l'Education Nationale, France, (2018).

4. Philipp, R. P., Mathematics teachers' beliefs and affect, in F. K. Lester (Ed.), Second handbook of research on mathematics teaching and learning: A project of the National Council of Teachers of Mathematics, Vol. 1, pp. 257-317), Charlotte, NC: Information Age (2007).

5. Leder, G.C., Pehkonen, E., Törner, G., Beliefs: A Hidden Variable in Mathematics Education?, Springer, New-York (2002).

6. Engeln, K., Euler, M., \& Maaß, K., Inquiry-based learning in mathematics and science: a comparative study of teacher' beliefs and practices across 12 European countries, ZDM Mathematics Education, 45(6), 823-836 (2013).

7. Bandura, A., Self-efficacy: The exercise of control, New-York: Freeman and Company (1997). 
8. Maa $\beta$, K., \& Gurlitt J., Designing a teacher-questionnaire to evaluate professional development about modelling, in V. Durand-Guerrier, S. Soury-Lavergne \& F.Arzarello (Eds.), Proceedings of 6th Congress of European society for research in mathematics education. Lyon, France: University of Lyon (2009).

9. Cabassut, R., Diversity of teachers' beliefs on modelling through a French-Spanish comparison, Proceedings of International symposium on elementary mathematics teaching SEMT17, Charles University, Prague: Czech Republic (2017).

10. Tukey, J., Exploratory data analysis, Reading, MA: Addison-Wesley (1977).

11. MEN (Ministère de l'Education Nationale), Consultation sur les repères annuels de progression et attendus de fin d'année du CP à la 3e, Ministère de l'Education Nationale(2019).

12. Duval, R., A cognitive analysis of problems of comprehension in a learning of mathematics, Educational Studies in Mathematics, 61: 103-130 (2006). 